\title{
O feminino indelével nas palavras poéticas de Warsan Shire, Upile Chisala e Safia Elhillo
}

The indelible female in the poetic words of Warsan Shire, Upile Chisala and Safia Elhillo

Élen Rodrigues Gonçalves. UFJF Bárbara Inês Ribeiro Simões Daibert.

t a d e I UFJF

i t e r a t $\quad$ u $\quad$ a o u t r a t $\mathbf{a}$ v e s s i a 


\section{Resumo}

A primeira observação relativa à escrita literária relaciona-se ao próprio ato físico de escrever, condicionado a uma tensão corpórea que só é aliviada, acabada, quando a escrita é terminada. Esta, em si, liga-se profundamente a uma conjuntura histórica, visto que não é atemporal, tampouco impessoal ${ }^{1}$. Soma-se a isso o fato de que o escritor, ao conceber noções de pertencimento em meio à sociedade que o cerca, não pode isolar-se de tudo o que, de alguma forma, o sensibiliza. Considerando, portanto, que homem e sociedade coadunam-se sobremaneira, analisamos atentamente a escrita poética de Warsan Shire (Quênia), Upile Chisala (Maláui) e Safia Elhillo (Sudão), que está demasiadamente associada às suas vivências pessoais, bem como ao passado histórico de seus países de origem e às heranças culturais de seus antepassados, uma vez que a própria escrita carrega em si uma carga de urgência assaz relacionada ao momento sócio-político-cultural da sociedade contemporânea.

Palavras-Chave: Warsan Shire; Upile Chisala; Safia Elhillo; Escritas de gênero; Poéticas africanas diaspóricas

\section{Abstract}

The first observation related to literary writing is linked to the physical act of writing itself, conditioned to a body tension that is only relieved, finished, when writing is finished. It itself is deeply linked to a historical conjuncture, since it is not timeless, neither impersonal ${ }^{2}$. Added to this is the fact that the writer, when conceiving notions of belonging among the society that surrounds him, cannot isolate himself from everything that somehow sensitizes him. Considering, therefore, that man and society are very consistent, we carefully analyze the poetic writing of Warsan Shire (Kenya), Upile Chisala (Malawi) and Safia Elhillo (Sudan), which is too much associated with their personal experiences as well as to the historical past of its countries of origin and the cultural heritage of their ancestors, since the writing itself carries a load of a great urgency related to the socio-political-cultural moment of contemporary society.

Keywords: Warsan Shire. Upile Chisala; Safia Elhilllo; Gender writings; African diasporic poetics

1 SPILLERS, Hortense. "Writing and States of Emergency", 2015, p. 58.

2 Ibidem, p. 58. 
Estudamos a produção literária negra feminista associada à crítica negra feminista $^{3}$, uma vez que literatura e crítica caminham paralelamente, sobretudo, se considerarmos que a produção de feministas negras transformou as possibilidades de publicações a ponto de modificar o cenário literário ao final do século XX ${ }^{4}$. Nessa época, mergiu o comprometimento em se revisar criticamente o conceito de família e de corpo feminino esteticamente estandardizado pela sociedade. Além disso, tais autoras problematizam o termo "mulher negra", que, por muito tempo, foi diretamente associado a problemas sociais ${ }^{5}$, em meio às políticas de Estado, aos discursos acadêmicos, e mesmo aos movimentos sociais, caracterizando-se como subjetividades incapazes de produzir literária e culturalmente.

Por isso, escritas contemporâneas como as das poetas estudadas neste artigo são importantes, visto que elas se engajam ativamente para modificar os discursos de lar, reimaginando a maternidade, a beleza dos próprios corpos, a representação da pele negra, o carinho fraterno, a sexualidade. Enfim, analisar suas poéticas tem o objetivo de criar um espaço propício para um futuro radicalmente distinto, envolvido especialmente com o respeito e com a promoção da diferença.

Em uma espécie de cartografia poética da humanidade, tais poetas são capazes de descentralizar as relações de poder na urgência de retirar do centro a atenção dada à Europa e/ou aos Estados Unidos, e, em contrapartida, movimentar, da margem, os povos do Terceiro Mundo. Chisala, natural do Maláui, Elhillo, original do Sudão, e Shire, nascida no Quênia, delineiam, dessa forma, uma realidade que, mais do que ser polarizada por linhas dicotômicas em relações de poder e de resistência, entrevê vozes, antes silenciadas, erguendo-se perenes, em meio à sociedade multicultural e hibridizada, para falar de gênero, cor, raça, classe, sexualidade, nacionalidade. Carole Boyce Davies, na obra Moving beyond boundaries (1995), comenta sobre a necessidade de não só falar da condição do silenciado, mas de que forma esse sujeito pode ser ouvido ao transgredir sistemas opressores, especialmente em se tratando da voz feminina negra, quando passa a ser ouvida. Para a autora, corre-se um grande perigo de se criar, sobre essa voz, uma escuta seletiva ou mesmo um mal-entendido ${ }^{6}$. De acordo com Davies, mesmo que seja agenciado o silenciamento, mulheres negras, em especial, têm erguido

3 Mesmo que muitas autoras negras feministas citadas neste artigo não se dediquem especificamente à crítica literária, seus debates podem ser analisados em convergência com as temáticas trabalhadas nos poemas.

4 GUMBS, 2008, p. 43.

5 GUMBS, 2008, p. 47.

6 DAVIES, Carole E. Boyce. "Hearing black women's voices: transgressing imposed boundaries", 1995, p. 3. 
sua voz e, ainda que operada de forma silenciosa, se edifica eloquentemente. Essa voz, ainda que proferida em silêncio, explica o passado de violência epistêmica, exercida física e psicologicamente, sobre as mulheres negras ao longo da história.

Dessa forma, a transformação do silêncio para a linguagem e ação é crucial para que a sua fala ganhe credibilidade e seja ouvida. Segundo a autora, soma-se a isso a concepção de que, em lugares públicos, predominam a valorização e a presença da voz masculina, carregada de racionalismo, de falta de emoção, de argumentos, de desenvolvimento lógico etc. ${ }^{7}$. Em contrapartida, emudecidas e confinadas em locais privados e domésticos, as mulheres, quando muito, são vagamente toleradas para tratar de assuntos concernentes ao lar, aos filhos ou aos afazeres domésticos.

Sobre esses silenciamentos, Davies relata alguns exemplos: "por muito tempo, houve certos problemas que eram considerados privados e, portanto, indizíveis: estupro, estupro por conhecido, estupro no casamento, abuso sexual, incesto, violência

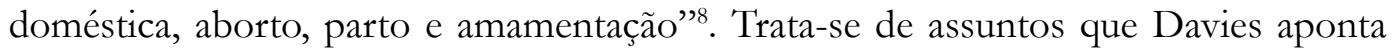
como sendo tratados em voz alta por mulheres negras em locais públicos. Essa mudança permite o empoderamento feminino, mesmo que ainda haja, em resistência, um movimento para a "surdez estratégica" .

Tal empoderamento, concedido pelo agenciamento de voz, é de suma importância para que a mulher negra possa falar de si, visto que, segundo Davies, mesmo no âmbito acadêmico, toda a narrativa de mulheres escravizadas no passado foi contada por homens brancos, negros ou mulheres brancas, de forma que se pode afirmar que a experiência de opressão e submissão vivida por mulheres negras, ao longo da história, é travestida de mentira:

Quando uma mulher negra se levanta na multidão para falar, (ou se apresenta publicamente), ela tem que lutar contra todos os significados históricos e culturais sobre ela até mesmo para começar a falar, e, então, o conteúdo de seu discurso já é enquadrado como não-fala ou desimportante ${ }^{10}$.

7 Ibidem, p. 4.

8 Ibidem, p. 4. Tradução nossa para: "for a long time, there were certain issues which were considered private and therefore unspeakable: rape, date rape, marital rape, sexual harassment, incest, domestic violence, abortion, childbirth, and breast-feeding".

9 Ibidem, p. 4. Tradução nossa para: "strategic deafness".

10 Ibidem, p. 5. Tradução nossa para: "when a black woman gets up in a crowd to speak, (or presents herself publicly), she has to battle all the cultural and historical meanings about her even to begin to speak and then the content of her speaking is already framed as non-speech or not important". 
Dada essa realidade, a solução encontrada pela pesquisadora em meio a um sistema que insiste em silenciar a mulher negra é agir na contramão dessa perspectiva, falando e escrevendo. Dessa forma, pode-se desafiar a surdez, a cegueira e as distorções de compreensão daqueles que estão no poder.

Das barreiras impostas pela sociedade para impedirem que as mulheres negras possam expressar-se erguem-se, entre outras: geográficas, linguísticas, ideológicas, midiáticas, religiosas, sexuais, econômicas, sociais, literárias, históricas, filosóficas ${ }^{11}$. Analisar, portanto, a trajetória de mulheres negras em contextos multiculturais implica perguntar-se de que forma elas de fato são ouvidas. Questionamento para o qual Davies já nos oferece resposta:

\footnotetext{
Como as mulheres negras são ouvidas? Por assertivamente e descaradamente transgredirem as barreiras impostas; por serem insistentes, solidárias; por falarem constantemente direta ou indiretamente, embora em múltiplas formas, mas sempre exigindo serem ouvidas; por desafiarem as aparentes incapacidades de audição; por constantemente criarem $^{12}$.
}

Importa-nos essa assertiva se considerarmos que, frequentemente, mulheres são silenciadas por variadas dominações: masculina, educação no seio familiar, nível escolar, relacionamentos abusivos, sociedades com valores tradicionais, posição econômica, enfim. Todavia, observamos, também, que a escrita de autoria feminina negra, dividindo experiências, desenvolvendo autoconsciência e autoconfiança, tem quebrado o silêncio e recebido a devida relevância. Aprendendo com gerações passadas e nelas inspirando-se para formar gerações futuras sem perpetuar costumes antigos, a escrita de autoria feminina negra está movimentando-se da posição de objeto para sujeito e, finalmente, reconhecendo a natureza impotente do silêncio quando a fala é finalmente proferida.

O mundo pode muitas vezes parecer hostil especialmente para africanos, negros e mulheres. Warsan Shire, Upile Chisala e Safia Elhillo são mulheres, negras e africanas e, como intelectuais, a primeira vivendo na Inglaterra e as outras duas, nos Estados Unidos, leem e estudam grande parte do pensamento canônico político e social escrito majoritariamente por homens brancos, entre os quais se nota um movimento de invisibilização da figura negra, bem como de silenciamento de suas

11 Ibidem, p. 9.

12 Ibidem, p. 9. Tradução nossa para: "How do black women get heard? By assertively and bold-facedly transgressing the imposed boundaries; by being insistent, supportive; by speaking constantly directly or indirectly, though in multiple forms but always demanding hearing; by challenging the pretended disabilities of hearing; by constantly creating". 
vozes. Nesse contexto, sobrepuja-se o engajamento de mulheres de cor do Terceiro Mundo, especialmente, porque uas falas não se restringem ao feminismo, pelo contrário, estendem-se a questões relacionadas às lutas "contra o racismo, sexismo, colonialismo, imperialismo e o monopólio de capital" ${ }^{13}$.

Trazer à tona a escrita de tais poetas é, portanto, essencial em um contexto em que a presença da mulher no âmbito social, político e acadêmico é ainda hoje limitada, sobretudo, porque as três desvelam, em seus textos, os silêncios da História, entre os quais, a ideia concebida de que o silêncio do subalterno está muitas vezes relacionado à ausência de uma vOz que o represente e, consequentemente, à ausência de registro. A relevância de suas escritas poéticas está no fato de utilizarem o contexto de suas vidas, as realidades de seus entornos, as histórias de suas famílias e de seus países, para, a partir de então, revelar os processos globais e seus efeitos. A teórica indiana Gayatri Chakravorty Spivak também fez isso em Pode o subalterno falar? (2014), ao tornar a realidade de seu país como representativa do Terceiro Mundo, escolha que é explicada, para Rosalind Morris, em Can the subaltern speak? Reflections on the bistory of an idea (2010), como um "acidente de história pessoal"14.

O sujeito subalterno feminino é uma figura cuja ideologia divide-se em duas linhas abissais nas quais residem dois "suicídios" de sua identidade: esse se encontra entrelaçado e, muitas vezes, perdido em ideologias do Ocidente e do Oriente, quando, na verdade, seria necessário haver espaço para se reconhecer a não universalidade da posição ocidental; além disso, é preciso considerar o gênero na construção do sujeito ${ }^{15}$ que, sendo feminino, é relegado ao silenciamento.

Spivak critica fortemente autores ocidentais considerados Sujeitos, como Gilles Deleuze e Michel Foucault, que ocupariam, para ela, uma posição de poder pelo fato de que, por meio da linguagem, tiveram voz para poderem falar e serem ouvidos ${ }^{16}$. A questão da subalternidade, por sua vez, é indagada pela autora por meio de buscas de registros históricos, como a narrativa fragmentada da ativista Bhubaneswari Bhaduri, que tirou a própria vida em 1926, na Índia. Grosso modo, em sua obra, Spivak confronta a ideia de sujeito como agente reduzido à política de identidade ou a um multiculturalismo não analisado. Além disso, analisa o problema da outremização ${ }^{17}$,

13 MOHANTY, Chandra Talpade. Feminism Without Borders: decolonizing theory, practicing solidarity, 2003, p. 46. Tradução nossa para "against racism, sexism, colonialism, imperialism, and monopoly capitalism"

14 MORRIS, Rosalind C. Can the subaltern speak? Reflections on the history of an idea, 2010, s./p.

15 Ibidem, s./p.

16 Ibidem, s./p.

17 Spivak comenta sobre o fato de que o subalterno, em uma posição discursiva, tem o poder de 
desvendando as condições de agenciamento e de subjetividade, bem como a dupla função de representação.

Spivak discorre sobre os dois significados do termo "representação": um deles condicionado a um "falar por", recorrente na política, e outro a uma "re-presentação", presente na arte ou na filosofia ${ }^{18}$. Por meio dessa dualidade, a teórica considera que Deleuze comete um equívoco ao tratar da teoria sem representar (falar por) o grupo oprimido. O equívoco estaria no fato de que os dois sentidos do termo representação "no contexto da formação do Estado e da lei, por um lado, e da afirmação do sujeito, por outro - estão relacionados, mas não irredutivelmente descontínuos" ${ }^{19}$. Dessa forma, a autora conclui que a crítica voltada para a formação ideológica do sujeito, bem como a ideia de formação de consciência, poderia ser descartada, uma vez que se revela, "assim, a banalidade das listas produzidas pelos intelectuais de esquerda nas quais nomeiam subalternos politicamente perspicazes e capazes de autoconhecimento. Ao representá-los, os intelectuais representam a si mesmos como sendo transparentes"20, por realizarem uma declaração sobre um sujeito não representado, analisando-o em função do desejo e do poder.

Por meio dessa análise, Gayatri Spivak percebe, em meio ao contexto histórico, econômico e político da atualidade global, o papel da família nas relações sociais, sempre heterogêneo e controverso, porque pertencente a uma realidade patriarcal, cuja estrutura não permite a inclusão de uma coletividade monolítica de mulheres ${ }^{21}$ entre os oprimidos e cuja subjetividade é possível falar por si mesma contra um sistema também monolítico.

Retomando Bhubaneswari, cuja morte por suicídio foi encontrada por Spivak nos arquivos históricos, ressalta-se sua representatividade para o feminismo: primeiramente, por tornar-se parte de um grupo terrorista; além disso, pelo suicídio transgressivo. Ao tirar a própria vida, evidenciando marcas de independência em comparação às mulheres hindus de classe média do início do século XX, na Índia, Bhubaneswari vai de encontro às crenças religiosas e leis seculares de seu povo, desafiando a regra hindu de que suicídio só se permitia a homens ${ }^{22}$. Somando-se a

\footnotetext{
fala retirado, visto que sua voz é suplantada pelo discurso dominante, além disso, muitas vezes, o subalterno precisa recorrer ao discurso hegemônico, a fim de que seja ouvido. Portanto, sua voz sempre é intermediada pela de um outro que fala em seu nome.

18 Ibidem, p. 39.

19 Ibidem, p. 38-39.

20 Ibidem, p. 41.

21 Ibidem, p. 50.

22 Com exceção das satis, ou seja, o sacrifício de viúvas na Índia.
} 
isso, a fim de refutar qualquer hipótese de morte provocada por vergonha de possível gravidez, ela se suicidou no período menstrual.

Em todas essas circunstâncias, portanto, sua morte representa um poder de agenciamento e resistência contra a sociedade patriarcal. Ao longo das décadas, sua história foi interpretada de forma pejorativa ou mesmo romantizada. Isso ocorre, porque, para Spivak, "circunstâncias históricas e estruturas ideológicas conspiram para apagar a possibilidade de ser ouvido" 23 , especialmente para aquele que, na sociedade patriarcal, é outremizado. Diante disso, é de suma importância oferecer explicação e análise de uma narrativa da realidade estabelecida como normativa, considerando que o desenvolvimento do sujeito subalterno é muitas vezes dificultado pelo projeto capitalista. Eis, portanto, a urgente necessidade, por parte de pensadores, críticos e artistas como Shire, Chisala e Elhillo, de levantar questionamentos: como se pode acessar a consciência do povo hoje? Com que voz-consciência pode o subalterno falar? Essa seria, para Spivak, uma tarefa de medir silêncios.

O suicídio de Bhubaneswari é importante para Spivak, visto que, se a própria mulher, no contexto indiano, não tinha o direito de escolha de decidir morrer pelas próprias mãos, logo, ela não poderia exercer sua plena subjetividade, uma vez que não haveria agenciamento. Contudo, em contraponto com a ideia já formada de que a mulher não poderia assumir uma posição de fala, ao exercer seu poder de autonegação, como sujeito político, ela desafiou a oposição declarada entre lei (sujeito) e repressão (objeto), de forma que seu ato de suicídio distinguiu-se do silêncio e da inexistência.

Vale observar que, ainda hoje, o principal tema discutido nas agendas globais é a emancipação feminina ${ }^{24}$. Dessa forma, o discurso de Spivak, para quem a condição de subalternidade é menos uma identidade do que uma situação, é “o lugar estruturado a partir do qual a capacidade de acesso ao poder é radicalmente obstruída"25, tornase tão contundente, especialmente ao observarmos que esse caráter de outremização também ocorre na literatura de autoria negra feminina.

Para o crítico literário Thomas Bonnici (2011), é surpreendente hoje, na literatura anglófona - sobretudo no caso britânico - haver um consistente número de escritores negros produzindo no território. Esse movimento ganhou força a partir da década de 1950, com a independência dos países africanos de língua inglesa e as consequentes migrações para a Grã-Bretanha, contribuindo para encorpar o cenário

23 MORRIS, Rosalind C. Can the subaltern speak? Reflections on the history of an idea, 2010, s./p.

24 MORRIS, Rosalind C. Can the subaltern speak? Reflections on the history of an idea, 2010, s./p.

25 MORRIS, Rosalind C. Can the subaltern speak? Reflections on the history of an idea, 2010, s./p. Tradução nossa para: "it is the structured place from which the capacity to access power is radically obstructed". 
multirracial e multicultural, enriquecendo sobremaneira a literatura da época. Para Bonnici, tais autores têm-se empenhado, desde então, em tratar, em suas obras, de temáticas urgentes, como miscigenação, racismo, negociações culturais e hibridismos linguísticos, fazendo sobrepor o "eu-enunciador negro"26, normalmente marginalizado, silenciado e invisibilizado pela sociedade.

Ressaltamos que Bonnici inicia seu artigo explicando que elementos englobam a Literatura Negra Britânica atual: toda literatura produzida em língua inglesa por autores diaspóricos provindos do Caribe, da Guiana, da Índia, do Sudeste Asiático, da África e de outros povos que já foram antigas colônias britânicas ${ }^{27}$. Sendo assim, a literatura produzida por Warsan Shire pode hoje ser enquadrada no âmbito da literatura negra britânica, assim como as escritas de Safia Elhillo e de Upile Chisala, como literaturas negras norte-americanas. $\mathrm{O}$ autor observa que, embora a Literatura Negra Britânica seja hoje largamente estudada e analisada, por muito tempo foi ignorada segundo Bonnici, até meados do século XX - "devido à outremização, à degradação e ao analfabetismo em que os sujeitos colonizados foram relegados pelos colonizadores do Império Britânico"28.

O processo de descolonização promovido pela independência da Índia e do Paquistão, a partir da primeira metade do século XX, promoveu profundas transformações na literatura britânica, até então "hegemonicamente branca e anglocêntrica" 29 , e ganhou ainda mais força a partir da década de 1960, com os movimentos pelos direitos civis desencadeados nos Estados Unidos, iniciando um período de incentivo a produções literárias britânicas de autoria negra. Nesse período, aponta Bonnici, também surgem as produções de várias outras vozes "especialmente (semi)autobiográficas femininas, sobre a condição da mulher imigrante negra no Reino Unido [...], [que] destacam-se por retratar a educação multicultural na sociedade britânica carregada de racismo e preconceito"30.

A virada do século XX para o XXI testemunhou a entrada dessa literatura no âmbito acadêmico interessado em analisar as variadas problemáticas tratadas em tais obras e que, para Bonnici, não era mais considerada, para a crítica literária, uma produção de característica subalterna, mas uma expressão literária considerada literatura britânica como qualquer outra do cânone. Ainda assim, Bonnici ressalta

26 BONNICI, Thomas. "Literatura negra e seu contexto britânico". Cadernos de Estudos Culturais, 2011, p. 170.

27 Ibidem, p. 170.

28 Ibidem, p. 173.

29 Ibidem, p. 174.

30 Ibidem, p. 176. 
que, no âmbito acadêmico, em comparação, especialmente, com as universidades americanas ou europeias, a Literatura Negra Britânica é relegada a segundo plano nas grades curriculares das universidades britânicas ${ }^{31}$.

A dificuldade de se abrir espaço para a introdução desse "novo cânone literário" 32 , segundo o autor, se dá porque "a herança imperial britânica e o racismo encoberto ainda permanecem e há um longo caminho para a sociedade britânica em geral e a comunidade universitária britânica em particular se tornarem realmente multiculturais" $" 33$. Somado a isso, Bonnici aponta para o fato de haver poucos intelectuais negros nas universidades que ensinem literatura e, quando as questões de gênero são levadas em consideração, esse aspecto é ainda mais agravado.

O paradoxo se dá, porque, em vista de uma sociedade cada vez mais multicultural e hibridizada, sobressai, em contrapartida, a falácia de uma democracia racial que se esquece do discurso dos direitos humanos e de uma ética de responsabilidade, ligados às causas raciais e de gênero, capazes de evitar as armadilhas do liberalismo darwinista social. Contestação política e luta de classe, à luz da ética de responsabilidade, confrontam a forma como temos moldado cotidianamente o outro em prol de uma representação do sujeito cuja imagem questione a sua condição como subalterno.

As obras das poetas estudadas neste artigo, por sua vez, exercem esse poder de agenciamento desejado e defendido por Spivak, por desafiarem os discursos hegemônicos e utilizarem a palavra poética para pensar a realidade histórica a partir de uma prática intervencionista, questionadora e engajada. Mesmo que, para Spivak, ao fim, não exista um espaço de representatividade no qual o subalterno, especialmente a mulher subalterna, possa realmente ser ouvido, talvez, o próprio fracasso de tentativa de representação se torne uma forma de escuta. Ainda assim, nenhuma de nós escapa a essa responsabilidade ética de ação, considerando que estamos todas imersas nesse sistema de representações que nos posiciona em condição de desigualdade em relação ao outro, sobretudo em relação às mulheres mais pobres do Terceiro Mundo, presas entre a tradição e a modernidade.

Por serem migrantes, terem acesso à educação, serem intelectuais e conceberem

\footnotetext{
31 Ressaltamos, também, que o mesmo acontece com a Literatura Negra Brasileira, ainda marginalizada e pouco estudada no âmbito acadêmico, a despeito da Lei 10.639/03 com o objetivo de promover as relações étnico-raciais na escola, a despeito da inserção do ensino de História e Culturas Africanas e Afro-brasileira nas Diretrizes Curriculares Nacionais, a fim de valorizar as diferenças e diminuir o histórico de racismo, bem como a institucionalização de um espaço escolar majoritariamente branco, eurocêntrico, excludente.

32 Ibidem, p. 180.

33 Ibidem, p. 181.
} 
pensamento crítico, as poetas, embora não possam ser consideradas sujeitos subalternos, é perceptível nelas esse desejo de ética de responsabilidade, que ela nunca pode estar dissociada dos estudos subalternos de gênero ${ }^{34}$. A literatura de autoria feminina negra marca a sistemática assimetria na hierarquia da sociedade e, mesmo quando a mulher é representada em sua universalidade - sempre cambiante -, essa representação é necessária para diferenciar historicidade, atenta às políticas de representação, por um lado, e à especificidade do contexto, por outro, convidando-nos a pensar como as "as hegemonias que se constituem e se legitimam no processo de consolidação do Outro como sujeito, atribuem-lhe 'autenticidade' e lhe dão voz ${ }^{35}$.

Safia Elhillo, Warsan Shire e Upile Chisala conseguem, ao mesmo tempo, engajar a particularidade e a historicidade dos contextos temporais e espaciais, sem deixar de criticamente contabilizar as transformações violentas do período colonial, bem como a efetivação de uma cultura hegemônica sobre a outra, considerada menor. Elas são capazes, assim, de pensar a história como um problema de alteridade, a fim de nos convidar a repensar as nossas pressuposições em torno de sexualidade, diferença sexual, racial, ou mesmo da própria humanidade em si.

Em The january children ${ }^{36}$, notamos, como dissemos, o entrelaçamento de fatos históricos e políticos do continente africano que, muitas vezes, se confundem com as vivências particulares da própria poeta. Sua coletânea de poemas explora assuntos que versam de noções que Elhillo concebe de si mesma, de seu lar - ou da reconstrução de um novo, quando em diáspora - como também de sua identidade.

Para Kwame Dawes, ${ }^{37} \mathrm{em}$ seu texto intitulado "Atlantic got your tongue?", há um exercício de negociação de "culturas, geografias e linguagens, em que tais negociações definem seu relacionamento com a ideia de exílio, bem como com a ideia de lar" ${ }^{\prime 38}$, em particular, porque suas raízes estão cravadas em geopolíticas de desterro.

O eu poético de The january children muitas vezes se confunde com a própria Safia Elhillo, que estabelece uma interlocução apaixonada com o músico egípcio Abdelhalim Hafez (1929-77), que dedicou uma série de canções aos asmarani, e com o qual ela mantém contato, questionando, explorando e reconstruindo seu senso de identidade ao longo de sua obra. Tal prática é importante, visto que, "para Elhillo, essa identidade

34 MORRIS, Rosalind C. Can the subaltern speak? Reflections on the history of an idea, 2010.

35 Ibidem, s./p. Tradução nossa para: "the hegemonies that constitute and legitimate themselves in the process of consolidating the Other as subject, attributing to it 'authencity' and giving it voice".

36 ELHILLO, Safia. The january children, 2017.

37 Ibidem.

38 Ibidem, p. x. Tradução nossa para: "cultures, geographies, and languages, and these negotiations define her relationship to the idea of exile and the idea of home". 
é inextricavelmente ligada a sua linguagem, sua política, sua raça e seu gênero. Ela confessa a ele sua alienação e incapacidade de ser sudanesa o suficiente [...]"39, como no poema intitulado "Candidatura para a posição de a garota de abdelhalim hafez"

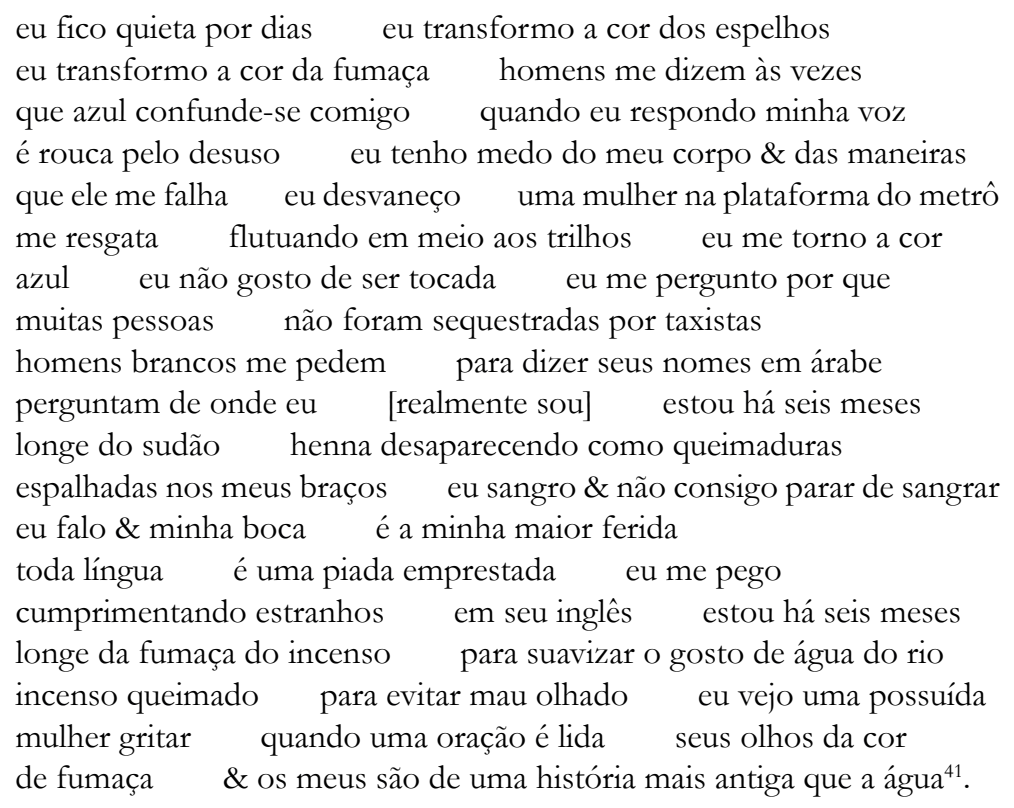

39 Ibidem, p. xi. Tradução nossa para: "For Elhillo, this identity is inextricably connected to her language, her politics, her race, and her gender. She confesses to him her alienation and her failure to be Sudanese enough [...]".

40 Ibidem, p. 7. Tradução nossa para: "application for the position of abdelhalim hafez’s girl".

41 Ibidem, p. 7. Tradução nossa para: "i go quiet for days i turn the color of mirrors/

i turn the color of smoke men tell me sometimes/

that blue becomes me when $\mathrm{i}$ answer my voice/

is hoarse from disuse i am afraid of my body \& the ways/

that it fails me i faint a woman on the subway platform/

catches me floating into the tracks i become the color/

blue i don't like to be touched i womder why/

more people have not been kidnapped by taxi drivers/

white men ask me to say their names in Arabic/

ask where i'm [really from] i am six months

/returned from sudan henna fading to look like burns

/dusted up my arms i bleed \& can't stop bleeding

/i speak \& my mouth is my biggest wound

/every language is a borrowed joke $i$ catch myself

/complimenting strangers on their English i am six months

/returned from incense smoke to soften the taste of river water

/incense burned to avert evil eye i see a possessed

/woman scream when a prayer is read her eyes the color 
A garota de Hafez, conforme o eu poético passa a autointitular-se, como no poema transcrito, quer ser reconhecida como uma mulher amada, embora se encontre em constante conflito consigo, acostumada ao silêncio que é viver em outra cultura e falar em outra língua. Da mesma forma que Abdelhalim Hafez - um cantor, compositor e ator que, em vida, recebeu visibilidade internacional -, o eu poético vive dividido entre o Sudão e o país que a faz passar dias em silêncio, visto que a língua lhe é estranha.

Sudão, no poema, seria uma invenção ${ }^{42}$, uma vez que configura um espaço que permite à poeta performar uma ideia particular de lar, ao mesmo tempo em que pode chorar por um lugar que, para ela, não é mais de chegada, tampouco de partida, mas de travessia. O país para o qual o eu poético permanece regressando, seja em nome de laços afetivos, sanguíneos, linguísticos, seja culturais, também a obriga a reviver traumas que ainda se fazem presentes, de forma que a casa original transforma-se duplamente em símbolo de dor - nos momentos em que regressa - e de libertação toda vez que parte.

Contudo, vale ressaltar que tal libertação talvez se dê apenas em comparação às tradições de seu lar, visto que, ainda em diáspora, o eu poético encontra-se preso, por sua vez, a partir da impossibilidade de se parecer com o outro: pela forma do corpo, ou pela cor da pele, pelas marcas de sua cultura na própria pele, como a hena, indeléveis e fortes como queimaduras, pelo sotaque, facilmente perceptível quando a voz é proferida, enfim, pela carga de exotismo que carrega por tais características.

Por isso, seu abrigo ou seu consolo são encontrados nas canções de uma voz egípcia e, ao mesmo tempo, internacional, de Hafez. O cantor, assim como a poeta - ou o eu poético espelhado nela - habitam essa tenacidade de uma identidade multicultural e hibridizada. Não são mais completamente africanos, dadas às experiências culturais pelas quais vivenciaram, tampouco são completamente estranhos na nova cultura cuja língua aprenderam e com a qual se comunicam.

O Hafez reinventado e imaginado pela poeta, e com o qual se identifica, lhe dá forças para ser diferente, constatação que temos ao final do poema. Se ser uma mulher diaspórica é estar constantemente em busca ou em construção de um lar, Elhillo transcende essa necessidade ao reconhecer, nos próprios olhos, a força de uma história mais antiga que a água, portanto, embora sem vestígios, com uma força atávica fecundante da alma do eu poético, talvez a mesma água do atlântico que percorre para a reconfiguração de um novo lar.

/of smoke \& mine is a story older than water".

42 Ibidem, p. xviii. 
Como todo país africano recentemente independente e cujas noções de pertencimento estão sendo hodiernamente reconstruídas, notamos constantes conflitos identitários presentes nas poéticas produzidas pelos seus artistas mais jovens, divididos entre seu lar, suas tradições e raízes, e, em contrapartida, a nova vida estrangeira, diaspórica, que escolheram viver, denotando uma agitação interna que se manifesta poeticamente no confronto que pode haver, a partir das novas percepções de lar. $\mathrm{O}$ mesmo acontece com Elhillo, de acordo com Dawes:

Dessa forma, mesmo que ela reconheça e anseie por um senso de pertencimento o qual ela associa com lar, com a ideia de retorno, ela também luta com seu corpo, sua sensualidade, seu desejo, e tudo isso está contido na ideia de sangue. Sangue que é rico na combinação de rebeldia, vergonha, bem como na noção de seus primórdios, seus sentidos de poder e de lugar ${ }^{43}$.

Semelhante questão é ampliada no poema intitulado "encontro noturno com abdelhalim hafez" ${ }^{44}$ :

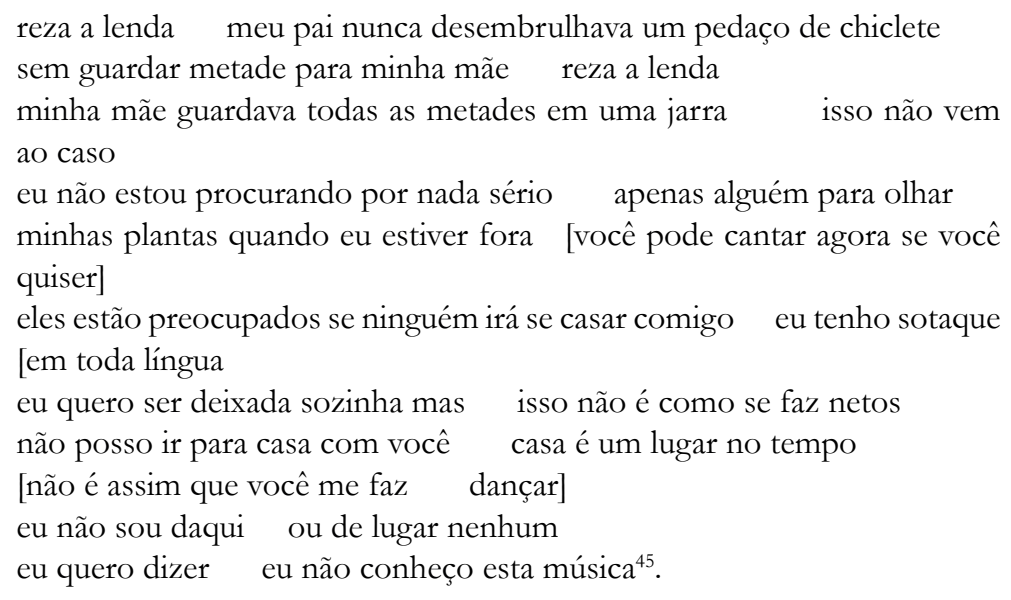

43 Ibidem, p. xiii. Tradução nossa para: "So even she recognizes and longs for the sense of belonging that she associates with home, with the idea of return, she is also wrestling with her body, her sensuality, her desire, and all that is contained in the idea of blood. Her blood is rich with a combination of defiance, shame, and the notion of her beginnings, her senses of power and place."

44 Ibidem, p. 21. Tradução nossa para: "date night with abdelhalim hafez”.

45 Ibidem, p. 21. Tradução nossa para: "the story goes my father would never unwrap a piece of gum /without saving half for my mother the story goes

/ my mother saved all the halves in a jar that's not the point

/i'm not looking for anything serious just someone to watch

/my plants when I'm gone [you can sing now if you want to]

/they're worried no one will marry me i have an accent in every language 
Embora a garota de Hafez queira ser objeto de devoção em suas canções (como notamos pelo fato de o cantor ser citado em mais de um de seus poemas), não consegue encontrar identificação com o padrão feminino esperado: a mulher que busca casar e ter filhos, sendo a solidão do eu poético, nesse caso, uma busca almejada. Essa diferenciação revela o choque estabelecido entre os dois sentimentos de desejo inconciliáveis: por um lado, viver uma vida própria, autônoma e independente, precisando de alguém apenas em momentos permitidos por ela própria (como para cuidar de uma planta); por outro, obedecer aos preceitos das tradições e do que sua família espera de si.

Ambas as narrativas encontram espaço na poética de Elhillo, que, em meio às memórias pessoais, encontra meios de permanecer em seu lar e, simultaneamente, partir dele. Seu diálogo com Hafez, seu direto interlocutor, torna-se uma espécie de abrigo por meio do qual a poeta pode depositar suas inseguranças e, ao mesmo tempo, libertar-se de seus traumas.

Em ambos os poemas analisados nessa subseção, notamos que pesa, em Elhillo, a necessidade de questionamentos que desestruturem verdades aceitas e que tentam reimaginar um mundo onde as pessoas de cor, especialmente mulheres, tenham voz; ainda que a poeta se sinta estrangeira em seu próprio país, é capaz de falar em sotaque, mesmo na língua materna, devido ao fato de estar, também, sempre em trânsito entre mais de um lar.

Para considerar que as poetas não escrevem apenas poesia, mas transmitem, sobretudo, uma ideia, necessitamos refletir sobre o problema da outremização, desvendando as condições de agenciamento e de subjetividade, bem como a dupla função de representação, de que fala Spivak. Tais poetas configuram, ao nosso ver, identidades em diferença, visto que elas são capazes de levantar, a um só tempo, duas problematizações: a primeira, relacionada às narrativas e políticas de identidades e a segunda, à ética de alteridade.

Nesse ínterim, Warsan Shire busca pensar a história não só como uma narrativa de identidade, mas especialmente, como um problema de alteridade, de forma que engaja a particularidade dos contextos temporais e espaciais, sem reproduzir discursos de identidade homogênea. Portanto, ao escrever sobre a mulher, cuja história muitas vezes assemelha-se com a sua própria e com a de seus antepassados - característica poética

\footnotetext{
/i want to be left alone but that's not how you make grandchildren

/i can't go home with you home is a place in time

/[that's not how you get me to dance]

/i'm not from here or from anywhere

/i mean to say i don't know that song".
} 
semelhante à de Elhillo e Chisala -, ainda assim, não pressupõe uma generalização, tampouco um constante e indiferenciado retrato da realidade pós-colonial; na verdade, contabiliza as transformações violentas e as marcas do colonialismo na contemporaneidade a partir da subjetividade feminina. Notamos essa crítica em "A boca de Maymuun" ${ }^{\prime 4}$ :

Maymuun perdeu o seu sotaque com a ajuda de sua Community College local.

Várias noites ela me faz ligações interurbanas para discutir os prós e os contras de esquentar melaço no micro-ondas para remover pelos do corpo. Sua nova voz é sofisticada. Ela foi levada para dançar na frente de estranhos. Ela mora ao lado de um dominicano que lhe fala em espanhol toda vez que se encontram nos corredores. Eu sei que ela sorri para ele, dentes da frente manchados de flúor da água de casa. Ela está tendo novas experiências. Nós entendemos. Nós recebemos as suas fotos de pé em uma ponte, o cabelo que ela odiou em toda sua vida, escorrido como um desfiladeiro. Semana passada sua secretária eletrônica atendeu. Eu imaginei-a levantada pela cintura, calçando meias, aprendendo a beijar com sua nova língua ${ }^{47}$.

Pela identidade multicultural e transnacional de Maymuun, Warsan Shire mostra como a personagem é capaz de rapidamente redefinir a ideia de seu lugar de pertencimento, uma vez que o eu poético sustenta, ao mesmo tempo, um caráter afetuoso e conflituoso em seu íntimo, quando observa cuidadosamente as mudanças físicas e comportamentais de Maymuun, questionamentos aparentemente singelos, mas cujas reflexões perpassam por indagações sobre identidades raciais e diaspóricas em constante busca por aceitação e representatividade na sociedade.

Como poeta africana anglófona em cujas temáticas trata de questões como a angústia pela busca de pertencimento, espacial ou simbólico, a violação do corpo feminino - nesse caso representado pela obediência aos padrões pré-estabelecidos pela sociedade ocidental, como o cabelo liso e o corpo depilado, entre outros aspectos -,

46 SHIRE, Warsan. Teaching my mother how to give birth, 2011, p. 10. Tradução nossa para: "Marymuun's Mouth".

47 Ibidem, p. 10. Tradução nossa para: "Maymuun lost her accent with the help of her local Community College./ Most evenings she calls me long distance to discuss the pros and cons of heating molasses in the microwave to remove body hair. Her new voice is sophisticated. She has taken to dancing in front of strangers. She lives next door to a Dominican who speaks to her in Spanish whenever they pass each other in hallways. I know she smiles at him, front teeth stained from the fluoride in the water back home. She's experiencing new things. We understand. We've received the photos of her standing by a bridge, the baby hair she'd hated all her life slicked down like ravines. Last week her answering machine picked up. I imagined her hoisted by the waist, wearing stockings, learning to kiss with her new tongue”. 
seu trabalho torna-se uma forma crítica de pensar a contemporaneidade hibridizada.

Em meio à realidade mais contemporânea, vem surgindo uma série de jovens poetas que escrevem em redes sociais - Tumblr, Twitter, Instagram - em meio às quais as três poetas se encontram inseridas e cujos poemas talvez recebam maior receptividade ainda devido ao alcance indiscutível da internet. Com efeito, para Amanda Hess, em seu artigo "Warsan Shire, a mulher que concedeu poesia ao Lemonade, de Beyoncé" 48 , ao referir-se à recepção de sua escrita no meio digital - e cujo pensamento pode ser transferido também à receptividade das escritas de Elhillo e Chisala -, declara: “[...] ela já é conhecida para muitos como uma voz contundente para a feminilidade negra e africana diaspórica - uma voz particular que ressoa na era digital"49.

Essa geração de jovens poetas, ao mesmo tempo em que revisita o passado histórico de sua família e de sua própria criação, lança um olhar ao futuro ${ }^{50}$, repensando o presente de forma crítica. Além disso, a voz representada a partir de um meio digital rompe as barreiras estabelecidas entre os textos e os nossos pensamentos, uma vez que integra os leitores globalmente, alcançando maior número de anônimos e empáticos por meio dos poemas, que são capazes, portanto, de lançar novas estratégias de discussões via internet sobre questões relacionadas a gênero, raça, classe, etnia, diáspora. Enfim, dessa forma, a rede é capaz de tornar-se o lugar-comum em que se podem discutir e problematizar traumas históricos da sociedade.

Em tom de prosa poética e com linguagem enxuta e fragmentada, que confere maior velocidade à leitura, característica própria das redes sociais, Shire abarca, em seus poemas, problemáticas que evidenciem a alteridade, o outro, muitas vezes, além de nosso alcance, mas que, ao mesmo tempo, constitui quem somos nós, "a alteridade em relação à qual somos, a um só tempo, gratos e incapazes de saber toda a extensão da nossa responsabilidade" ${ }^{51}$. Em "O primeiro beijo de tua mãe" 52 , nutrindo a ética de responsabilidade de que fala Spivak, Shire trata de assuntos considerados indizíveis em seu poema, como estupro e abuso sexual:

o primeiro garoto que beijou tua mãe mais tarde estuprou mulheres quando a guerra eclodiu. Ela se recorda ouvir sobre isso

48 HESS, Amanda. "Warsan Shire, the woman who gave poetry to Beyonce's 'Lemonade". The New York Times. 2016, s./p. Disponível em: https://www.nytimes.com/2016/04/28/arts/music/warsanshire-who-gave-poetry-to-beyonces-lemonade.html. Acesso: 11 março 2021.

49 Ibidem, s./p. Tradução nossa para:" [...] she is already known to many as a compelling voice on black womanhood and the African diaspora - one particularly resonant in the digital age".

50 OKEOWO, Alexis. "The Writing life of Warsan Shire, a young, prolific poet". The New Yorker, 2015.

51 MORRIS, Rosalind C. Can the subaltern speak? Reflections on the history of an idea, 2010, s./p. Tradução nossa para: "the otherness in relation to which we are both indebted and unable to know the full extent of our accountability".

52 SHIRE, Warsan. Teaching my mother how to give birth, 2011, p. 8. 
de teu tio, em seguida, foi para teu quarto e deitou-se no chão. Tu estavas na escola.

Tua mãe tinha dezesseis anos quando ele a beijou pela primeira vez.

Ela segurou o fôlego por tanto tempo que desmaiou.

Ao acordar, ela encontrou seu vestido molhado e grudando

em seu estômago, meias luas mordidas em suas coxas.

Nessa mesma noite, ela visitou uma amiga, uma garota

que fermentava vinho ilegalmente em seu quarto.

Quando tua mãe confessou Eu nunca fui tocada

dessa maneira antes, a amiga riu, boca ensanguentada de uvas,

então, mergulhou uma mão entre as pernas de sua mãe.

Semana passada, ela o viu dirigindo o ônibus número 18,

as bochechas dele como uma colina inchada, uma cicatriz de videira

[arrastando-se

pela sua boca. Tu estavas com ela, segurando um saco

de tâmaras em teu peito, ouviu-a soltar um gemido profundo

quando ela viu o quanto tu te parecias com ele.

Shire abre seu poema tratando de questões consideradas ainda muito fechadas na sociedade: sexualidade feminina, ainda hoje, considerada em algumas regiões, tabu indiscutível. No poema, tal tabu é tristemente descortinado ao longo de cada estrofe pela experiência vivida pela figura feminina sobre a qual nos fala o eu poético.

A ausência de controle sobre o próprio corpo evidencia-se, nesse caso, a partir da constatação de que a criança que segura o saco de tâmaras contra o peito carrega as semelhanças do homem que um dia beijara a própria mãe e, mais tarde, estupraria mulheres. Contudo, evidência clara na segunda estrofe do poema, a própria figura feminina retratada no poema também foi estuprada. A contribuição com temáticas como essa permite ampliar as discussões quase sempre sequer mencionados na sociedade contemporânea.

Mesmo em forma de linguagem poética, Shire, como sujeito de direito, representa a capacidade de poder falar por e para outros que não têm voz. Trata-se, portanto, de uma representação ética, visto que se fala em nome de um outro e se exerce, por isso, uma responsabilidade sobre sua imagem. Contudo, ressaltamos que, não raro, tal representação ética pode ser perigosa, considerando que, se a sociedade atual legitima-se pela categoria da diferença, naturalizando a ideia de que há geralmente uma suposta relação de superioridade e inferioridade entre as pessoas, deve-se estar atento pra não se perpetuar essa noção deturpada, tampouco retirar a voz do que foi silenciado.

Enquanto Ehillo trata da dificuldade de uma identidade diaspórica amar e ser amada em meio às diferenças, apegando-se, portanto, a uma figura idealizada, mas com cuja identidade transnacional identifica-se; enquanto Shire revela assuntos difíceis e 
delicados para serem discutidos, mesmo em uma sociedade considerada cada vez mais aberta a discussões, sem causar desconforto - abusos travestidos de formas de amor, como em Maymuun, que "violenta", de certa forma, seu corpo para adaptar-se à nova vida, ou a figura feminina retratada no segundo poema analisado, que sofre abuso sexual; Chisala, por sua vez, de uma forma mais branda, mas não menos contundente, representa a voz da mulher negra que se eleva em meio aos padrões sociais pré-estabelecidos, com os quais não se identifica, a fim de revelar a aceitação do corpo feminino negro não estandardizado, mas singular e especial em sua beleza única.

Livre da obediência a um padrão de beleza a ser seguido pela sociedade ocidental, o eu poético do poema de Chisala engaja-se em um espaço poético que a ajuda a redefinir padrões de beleza por meio da aceitação da diversidade:

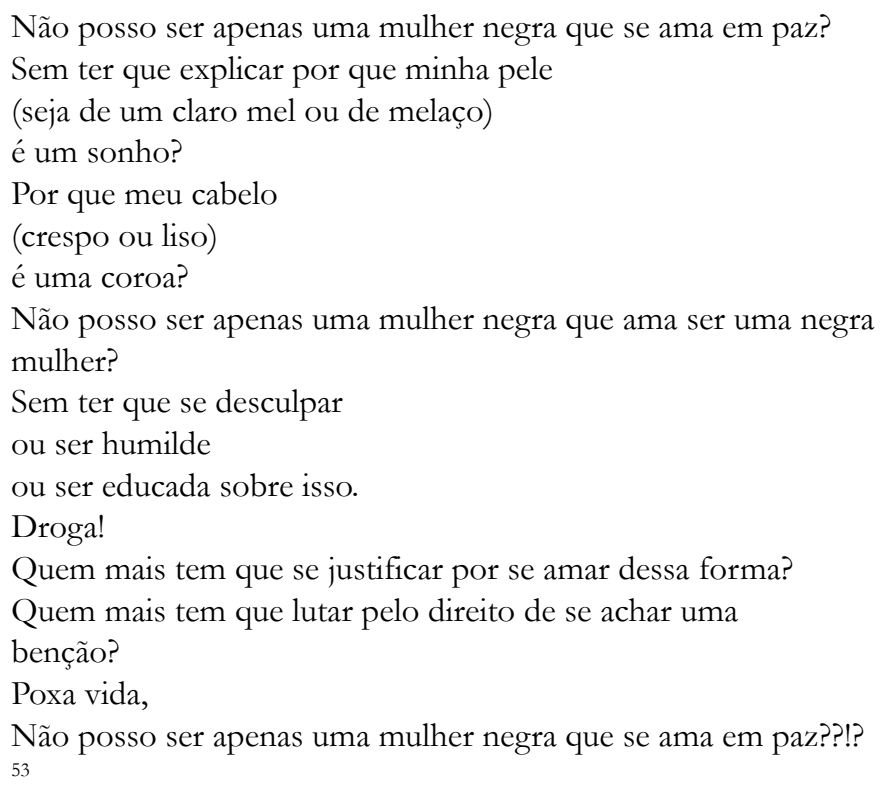

Em meio à realidade multicultural, transnacional e diaspórica, é profundamente necessário dar atenção às diferenças, ou mais, como evidencia o poema acima, permitir que as diferenças sobressaiam na sociedade em toda sua beleza e diversidade.

Os questionamentos lançados pelo eu poético, de encontro à personagem Maymuun, de Shire - que se esforça para atender aos padrões de beleza estabelecidos

53 CHISALA, Upile. Nectar, 2017, p. 18. Tradução nossa para: “Can’t I just be a black woman that loves herself in peace?/ Without having to explain why my skin/ (be it light honey or molasses)/ is a dream?/ Why my hair/ (coarse or sleek)/ is a crown?/ Can't I just be a black woman that loves being a black/ woman?/ Without having to be sorry/ or humble/ or polite about it./ Damn it!/ Who else has to justify loving themselves like this? / Who else has to fight for the right to call themselves a/ blessing?/ Goodness,/ Can't I just be a black woman that loves herself in peace??!?”. 
e perpetuados pela sociedade branca dominante -, por exemplo, são necessários para ajudar a moldar um novo pensamento global, a fim de se nutrir um senso de unidade sem subjugação de qualquer raça ou etnia. Para isso, se normalmente o corpo sexuado da mulher é espaço para violência, nesse caso, torna-se um ambiente para a possibilidade de formação de uma nova autoconsciência feminina que vai ao encontro das mulheres de nosso próprio tempo, caracterizadas por suas particularidades e individualidades.

A escrita de Chisala, portanto, oferece-nos uma certa forma de distorção do presente a partir da reescrita da realidade vista por uma nova perspectiva. Por meio da literatura, abrem-se novos mundos possíveis a partir de uma trajetória que movimenta o lugar de marginalidade para o empoderamento. Segundo 'Molara Ogundipe-Leslie (poeta, crítica literária, ativista e feminista nigeriana), em seu ensaio "Women in Africa and Her Diaspora: From Marginality to Empowerment" ${ }^{54}$, não só as africanas, mas as mulheres de cor de todo o mundo sofrem subordinações e discriminações pela questão de gênero. Por esse motivo, é necessário que surja entre elas um movimento global de sororidade, a fim de que se destituam as marcas comuns de exploração e subordinação que as unem.

Para a autora, essas marcas têm variadas caracterizações: opressão biológica, patriarcado, exclusão, exploração abusiva do trabalho (jornadas duplas, triplas), perseguição por exigirem equidade e por procurarem empoderamento ${ }^{55}$. Para tratar de tais problemáticas, escritas africanas diaspóricas têm maior sensibilidade, visto que "mulheres africanas em diáspora desejam, em meio aos ideais comunitários, respeito e reconhecimento por suas contribuições em suas comunidades como indivíduos com identidades coletivamente reconhecidas" $" 56$.

Logo, poetas como Chisala, Elhillo e Shire têm dado voz às mulheres negras historicamente esquecidas ao longo dos séculos, empoderando-as e dando-lhes oportunidade de calar o silêncio paralisante, representando-as em sua coletividade, como se pode perceber no poema a seguir:

\footnotetext{
Às vezes nós ficamos exaustas, ficamos cansadas de todos os lares que temos que trazer conosco para um quarto. Todas as línguas em nossos ventres. Os países em nossos pés. A cultura
}

54 OGUNDIPE-LESLIE, 'Molara. "Women in Africa and Her Diaspora: from marginality to empowerment", 1995, p. 15.

55 Ibidem, p. 15.

56 Ibidem, p. 16. Tradução nossa para: "women of Africa and her diaspora desire, within communitarian ideals, respect for and recognition of their contributions to their communities as individuals with collectively acknowledged identities". 
entrelaçada com as nossas espinhas; às vezes pesada, às vezes parte de nossos corpos.

Mas que benção isso é.

Nós viemos de muitas. Nós apoiamos muitas. Nós confiamos em muitas. Nós somos muitas. ${ }^{57}$

No poema de Chisala, a mulher africana diaspórica carrega em si várias versões de sua própria identidade, ou mais, em meio ao trânsito e por meio do contato de outras mulheres, toda identidade feminina torna-se múltipla, em diálogo com outras vozes. Por isso, como declara o eu poético, "nós somos muitas". A união feminina permite a formação de espaço em que suas vozes sejam ouvidas, visto que se cria, entre elas, a responsabilidade ética de um reconhecimento do lugar que cada mulher ocupa na sociedade.

Conforme declara Ogundipe-Leslie, "nosso trabalho, escritas e exortações como mulheres em variadas formas e mídias mostram que queremos acabar com nossos silêncios e falar nossas verdades como as conhecemos" ${ }^{\text {"58 }}$. Esse anseio que se encontra tanto nos poemas de Chisala, quanto nas escritas de Elhillo e Shire, sobretudo nas palavras de Ogundipe-Leslie, evidencia o anseio pelo poder que pode ser alcançado a partir da palavra poética.

Essa exerce tal influência que seus ideais defendidos nos textos literários podem tornar-se uma espécie de "estilo de vida" a ser seguido por leitoras. Esse sentimento fortalece a luta travada até então por mulheres contra a exploração e a opressão sexistas, contra os problemas de gênero, profundamente associadas também às questões de raça e classe.

57 CHISALA, Upile. Nectar, 2017, p. 83. Tradução nossa para: "Sometimes we are exhausted, we are tired of all the homes/ that we have to bring with us to a room. All the languages/ in our bellies. The countries in our feet. The culture/ entwined with our backbones; sometimes heavy,/ sometimes part of our bodies.// But what a blessing it is.// We come from many. We support many. We rely on many./ We are many."

58 OGUNDIPE-LESLIE, 'Molara. "Women in Africa and Her Diaspora: from marginality to empowerment", 1995, p. 17. Tradução nossa para: "Our work, writings and exhortations as women in various forms and media show that we want to end our silences and speak our truths as we know them". 


\section{Referências}

BONNICI, Thomas. Literatura negra e seu contexto britânico. Cadernos de Estudos Culturais. v. 3, n. 6, p. 169-190, 2011. Disponível em: http://www.seer.ufms.br/index. php/cadec/article/view/4564. Acesso em: 12 nov. 2018.

CHISALA, Upile. Nectar. s/1, 2017.

CHISALA, Upile. Soft Magic. s/1, 2015.

DAVIES, Carole E. Boyce. Hearing black women's voices: transgressing imposed boundaries. In: DAVIES, Carole Boyce; OGUNDIPE-LESLIE, 'Molara. Moving beyond boundaries. International dimensions of black women's writing. New York: New York University Press, 1995. p. 3- 15.

DAWES, Kwame. Atlantic got your tongue? In: ELHILLO, Safia. The january children. Lincoln: University of Nebraska, 2017. p. ix-xviii.

ELHILLO, Safia. The january children. Nebraska: African Poetry Book Series, 2017.

MOHANTY, Chandra Talpade. Feminism Without Borders: decolonizing theory, practicing solidarity. Durham, London: Duke University Press, 2003.

MORRIS, Rosalind C. Can the subaltern speak? Reflections on the history of an idea. New York: Columbia University Press, 2010.

OKEOWO, Alexis. The Writing life of Warsan Shire, a young, prolific poet. The New Yorker. 2015. Disponível em: https://www.newyorker.com/culture/culturalcomment/the-writing-life-of-a-young-prolific-poet-warsan-shire. Acesso em: $11 \mathrm{dez}$. 2018.

OGUNDIPE-LESLIE, 'Molara. Women in Africa and Her Diaspora: from marginality to empowerment. In: DAVIES, Carole Boyce; OGUNDIPE-LESLIE, 'Molara. Moving beyond boundaries. International dimensions of black women's writing. New York: New York University Press, 1995. p. 15-17.

SHIRE, Warsan. Teaching my mother how to give birth. UK: Mouthmark Series, 2011.

SPILLERS, Hortense. Writing and States of Emergency. In: DONAHUE, 
Christiane; BLEWETT, Kelly. The power of writing. Hanover, New Hampsire:

Dartmouth College Press, 2015. p. 57- 74. Disponível em: https://trueleappress. com/2017/12/18/working-bibliography-of-hortense-j-spillers/. Acesso em: 26 nov. 2018.

SPIVAK, Gayatri Chakravorty. Pode o subalterno falar? Tradução Sandra Regina Goulart Almeida, Marcos Pereira Feitosa, André Pereira Feitosa. Belo Horizonte: UFMG, 2014. 